\title{
Role of acetylation in nonalcoholic fatty liver disease: a focus on SIRT1 and SIRT3
}

\author{
Fatiha Nassir* (10 \\ Department of Medicine, Division of Gastroenterology and Hepatology, University of Missouri, Columbia, M0 65212, USA \\ *Correspondence: Fatiha Nassir, Department of Medicine, Division of Gastroenterology and Hepatology, University of Missouri, \\ Columbia, MO 65212, USA. nassirf@health.missouri.edu \\ Academic Editor: Amedeo Lonardo, Ospedale Civile di Baggiovara, Azienda Ospedaliero-Universitaria di Modena, Italy \\ Received: May 31, 2020 Accepted: July 24, 2020 Published: August 31, 2020
}

Cite this article: Nassir F. Role of acetylation in nonalcoholic fatty liver disease: a focus on SIRT1 and SIRT3. Explor Med. 2020;1:248-58. https://doi.org/10.37349/emed.2020.00017

\begin{abstract}
Nonalcoholic fatty liver disease (NAFLD) has become the most prevalent liver chronic disease worldwide. The pathogenesis of NAFLD is complex and involves many metabolic enzymes and multiple pathways. Posttranslational modifications of proteins (PMPs) added another layer of complexity to the pathogenesis of NAFLD. PMPs change protein properties and regulate many biological functions, including cellular localization, stability, intracellular signaling, and protein function. Lysine acetylation is a common reversible PMP that consists of the transfer of an acetyl group from acetyl-coenzyme A $(\mathrm{CoA})$ to a lysine residue on targeted proteins. The deacetylation reaction is catalyzed by deacetylases called sirtuins. This review summarizes the role of acetylation in NAFLD with a focus on sirtuins 1 and 3.
\end{abstract}

\section{Keywords}

NAFLD, sirtuin 1, sirtuin 3, acetylation

\section{Introduction}

Nonalcoholic fatty liver disease (NAFLD) has become the most prevalent liver chronic disease worldwide [1]. NAFLD consists of the accumulation of fat in the liver (steatosis) that might progress to nonalcoholic steatohepatitis (NASH), fibrosis, cirrhosis, hepatocellular carcinoma. NAFLD affects $25 \%$ of the global population; $1.5-6.5 \%$ is estimated to have NASH [2-5]. The pathogenesis of NAFLD is complex and implicates multiple factors, acting together in the development and aggravation of the disease [6, 7]. NAFLD has become a silent epidemic rising with the increase in obesity and insulin resistance $[6,8]$. The mechanisms involved in NAFLD include the excessive accumulation of fat in hepatocytes, impaired mitochondrial function, and mitochondrial damage, increased intracellular fat, oxidative stress, inflammation, cellular damage, apoptosis, and activation of fibrosis $[9,10]$. Apart from lifestyle modifications, no pharmacotherapy is currently approved to treat NAFLD despite the alarming health concerns. NAFLD therapies, currently being evaluated, target some aspects of metabolic enzymes and metabolic dysfunction. The discovery of posttranslational modifications (PTMs) of proteins (PMPs) added a new layer to the complexity of the mechanisms involved in NAFLD. PMPs 
represents a major protein diversification mechanism by which the cell increases the diversity of its proteome $[11,12]$. PMPs involve modifications that change protein properties and regulate many biological functions, including cellular localization, stability, intracellular signaling, protein-protein interactions, and protein function [11-13]. Several PMPs have been identified, including acetylation, glycosylation, phosphorylation, palmitoylation, ubiquitination, succinylation, and prenylation. This review summarizes the role of the deacetylases sirtuin (SIRT)1, and SIRT3 in NAFLD.

\section{Pathogenesis of NAFLD}

The liver plays an essential role in lipid metabolism [14]. The pathogenesis of NAFLD includes the accumulation of hepatic triglyceride as a result of increased flux of fatty acids (FAs) into hepatocytes, increased de novo lipogenesis (DNL), reduced export of lipids into lipoproteins, mitochondrial dysfunction, mitochondrial damage, oxidative stress and inflammation which lead to cellular damage, apoptosis, and fibrosis $[9,10]$. Insulin resistance increases hepatic DNL, reduces adipose tissue insulin sensitivity, and increases the flux of FAs to the liver [15]. Lipid export capacity and the oxidation of fat in the mitochondria increase to compensate for the increased FAs flux to the liver [15-17]. However, mitochondrial dysfunction eventually occurs, likely due to increased lipids and impaired electron chain activity $[10,18,19]$.

\section{Acetylation}

Acetylation of proteins is a key PTM, initially known to regulate transcription through modification of nuclear proteins $[20,21]$. The role of lysine acetylation has been extended to thousands of non-nuclear proteins, including metabolic enzymes [20,22-24]. Lysine acetylation regulates a wide range of cellular processes and metabolism [22]. Lysine acetylation consists of the addition of an acetyl group from acetyl-coenzyme A (acetyl-CoA) to a lysine residue within a protein. Large-scale proteomics studies identified over 3,000 acetylation sites [24-27]. More than 20\% of mitochondrial protein is acetylated in mouse liver [26]. Using high-resolution mass spectrometry, studies by Choudhary et al. [25] identified acetylation as a major PMP comparable to phosphorylation. Acetylation regulates metabolic pathways, including the tricarboxylic acid (TCA) cycle and FA metabolism [24]. The acetylation status of metabolic enzymes appears to be responsive to environmental, dietary, lifestyle factors providing mechanisms for rapid changes in protein properties in response to the cellular environment $[24,28]$. Acetylation of cellular proteins regulates their localization, stability, interaction with other proteins, and function [26, 29]. In addition to acetylation, a lysine residue in a protein can be subject to other PTMs, such as methylation, phosphorylation, ubiquitination, succinylation, and sumoylation. Modification of lysine residues by PTM may occur in a mutually exclusive manner suggesting an interplay between the different lysine modifications in the function of the regulatory protein $[13,30,31]$.

\section{Acetylation and NAFLD}

Although lysine acetylation was discovered about 50 years ago, it has regained more attention in recent years. Not much is known about the specific changes in the acetylation profile with NAFLD. However, protein acetylation pattern in fatty livers is significantly different from healthy livers [32]. Studies on the role of acetylation and NAFLD are emerging. The transcription factor, cyclic AMP-responsive element-binding protein 3-like 3-hepatocyte-specific (CREBH), is one example of the modulation of NAFLD by acetylation [33]. CREBH regulates many metabolic pathways, including lipolysis, fatty acid oxidation (FAO), and ketogenesis [34]. Defects in CREBH might directly lead to NASH and hyperlipidemia under an atherogenic high-fat diet (HFD) or fasting conditions [34, 35]. The P300/CBP-associating factor (PCAF) and SIRT1 are the acetyltransferase and deacetylase, respectively, that regulate CREBH [33]. The acetylation of CREBH by PCAF at lysine 294 is required for CREBH transcriptional activity and for maintaining hepatic lipid homeostasis in fasting states [33]. The carbohydrate-response element-binding protein (ChREBP) is another example of the modulation of NAFLD by acetylation. In a high-glucose state, ChREBP is acetylated by p300 at lysine 672 [36, 37]. Acetylation of ChREBP induces hepatic lipid accumulation by increasing the expression of lipogenic genes (Figure 1). These studies suggest that lysine acetylation is associated with hepatic steatosis. Since most studies on acetylation 
and NAFLD focused on the role of the deacetylases SIRT1 and SIRT3, this review will mainly summarize the role of SIRT1 and SIRT3 in NAFLD.

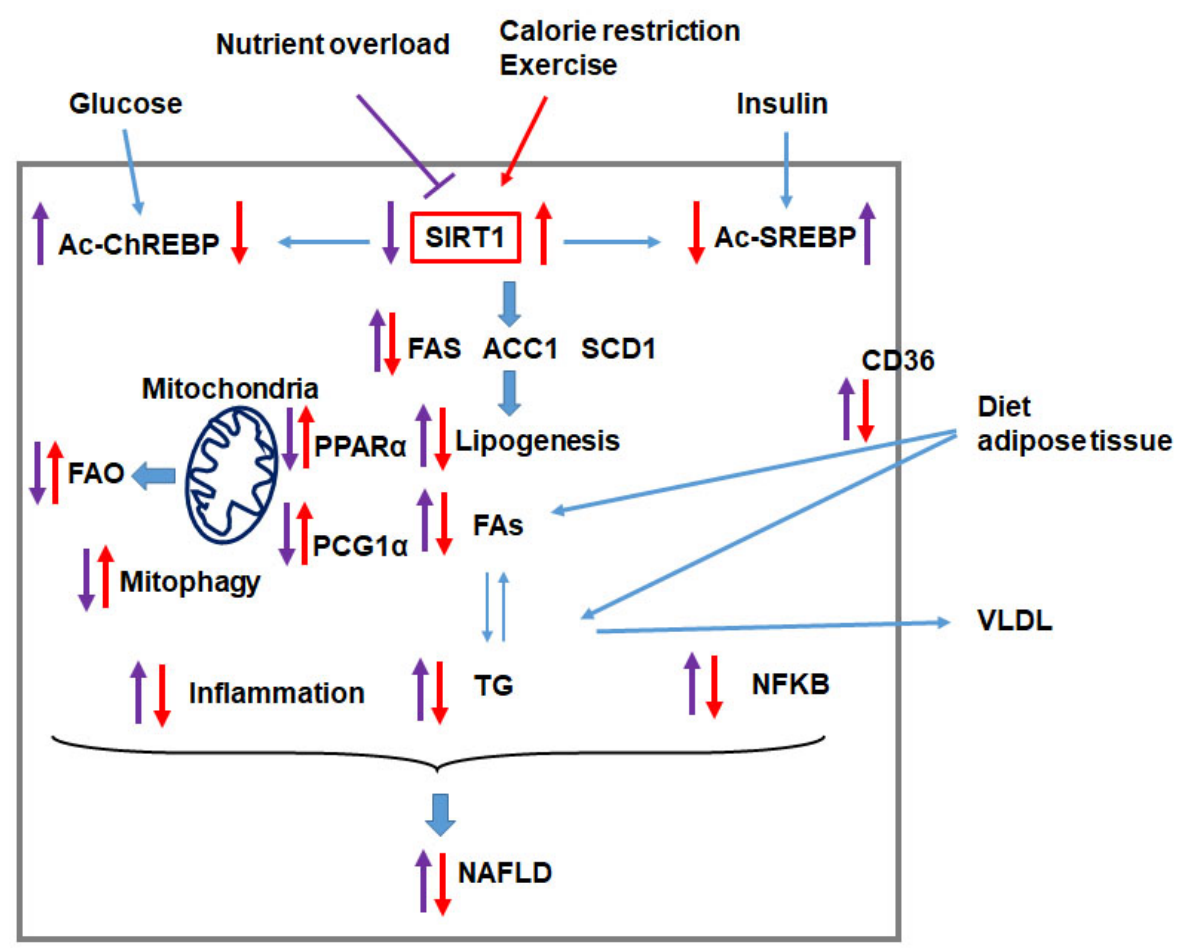

Figure 1. SIRT1 protects the liver from nutrient overload-induced NAFLD. Nutrient overload triggers metabolic reprogramming that leads to hepatic lipid accumulation and liver injury. Nutrient overload induces the hyper-acetylation of the transcription factors ChREBP (Ac-ChREBP) and SREBP (Ac-SREBP) leading to induction of lipogenic enzymes [FA synthase (FAS), acetyl-CoA carboxylase 1 (ACC1), and stearoyl-CoA desaturase-1 (SCD1)] and the peroxisome proliferator-activated receptors (PPARa)/ peroxisome proliferator-activated receptor $y$ coactivator-1 $\alpha(P G C 1 \alpha)$ pathway leading to increased FAs in the liver and reduced FAO. Nutrient overload also upregulates the FA transport protein CD36 and increases the uptake of FAs. Altogether, the reprogramming of these pathways leads to the accumulation of hepatic triglyceride (TG). On the other hand, lipid overload is associated with increased inflammation, reduced mitophagy, and induction of the NF-kappa B (NFKB) pathway, altogether leading to liver injury and the progression of NAFLD. Factors that upregulate SIRT1, such as calorie restriction and exercise, counteract the development and the progression of NAFLD. VLDL: very-low-density lipoprotein

\section{Sirtuins and NAFLD}

An increasing number of studies have shown the regulation of metabolic enzymes by the SIRTs. Mammalian SIRTs (SIRT 1-7) are seven members belonging to the silent information regulator 2 family with different subcellular functions. Sirtuins regulate cellular proteins through various PTMs. SIRT1 and SIRT3 are protein deacetylases that act as a critical metabolic/energy sensor, which directly links the product of metabolism to cellular activities involved in metabolic homeostasis [38-41]. SIRT1 and SIRT3 regulate hepatic carbohydrate and lipid metabolism, insulin signaling, and inflammation [20, 42, 43]. SIRT1 and SIRT3 use the product of cellular nicotinamide adenine dinucleotide (NAD) as a cofactor to post-translationally deacetylate cellular proteins and consequently link the metabolic status of the cell to protein function. Changes in sirtuin expression are critical in several diseases, including metabolic syndrome, diabetes, and NAFLD. Here we focus on the role of the most commonly studied deacetylases SIRT1 and SIRT3 in the regulation of NAFLD.

\section{SIRT1 and NAFLD}

SIRT1 regulates the acetylation of both histones and other cellular proteins. SIRT1 is expressed in the liver, pancreas, heart, muscle, and adipose tissue [44], and the protein is localized both in the nucleus and cytoplasm [44, 45]. SIRT1 plays an essential role in the pathophysiology of many metabolic diseases, including NAFLD [38, 46-49]. SIRT1 is downregulated in patients with NAFLD [43, 50]. SIRT1 has been shown to improve NAFLD in part through its effect on improving insulin sensitivity, its antihyperlipidemic, and its anti-inflammatory activities $[47,51]$. Nutrition overload impairs SIRT1 function by reducing cellular NAD levels [52], while calorie restriction increases NAD levels and activates SIRT1 [53, 54] (Figure 1). 
Interestingly, late gestation and early postnatal life exposure to excess dietary fat increase the susceptibility to develop NASH in adulthood, and this was associated with reduced SIRT levels and altered expression of genes involved in NAFLD [55-57]. Treatment of mice fed HFD with the polyphenol resveratrol that activates SIRT1, improves lipid metabolism, and decreases NAFLD and inflammation in the liver [58]. In HFD-induced hepatic steatosis, SIRT1 improves NAFLD by reducing DNL and increasing $\beta$-oxidation [59] (Figure 1). SIRT1 activates lipogenic enzymes through SIRT1-mediated deacetylation of transcription factors in the promoter of downstream genes. Two major transcriptional factors, sterol regulatory element-binding transcription factor 1c (SREBP-1c) and ChREBP, control triglyceride synthesis $[59,60]$. SREBP-1c and ChREBP activate lipogenic enzymes ACC1, FAS, and SCD1 (Figure 1). SIRT1 deacetylates and inhibits SREBP-1c activity [61]. siRNAmediated depletion of SIRT1 increases the acetylation of SREBP-1c and activates lipogenic enzymes [61]. However, adenoviral overexpression of SIRT1 in the liver decreases acetylated SREBP-1c levels and lipogenic gene expression [61]. PPAR $\alpha /$ PGC- $1 \alpha$ signaling pathway plays a significant role in the oxidation of fat in the mitochondria [62]. PGC- $1 \alpha$ is a transcriptional coactivator that induces the expression of PPAR $\alpha$ target genes [62]. SIRT1 increases the transcription of PPAR $\alpha$ and promote $\beta$-oxidation in the liver, mainly through its ability to deacetylate PGC-1 $\alpha$ (Figure 1) [63-65].

Damaged mitochondria are degraded by selective autophagy, called mitophagy. SIRT1 plays an important role in mitochondria by regulating mitophagy $[49,66]$. SIRT1 also mitigates HFD-induced fatty liver and liver injury by inhibiting the expression of the FA transport protein CD36 and the NF-KappaB signaling pathway (Figure 1) $[67,68]$. The available findings so far demonstrate that SIRT1 plays a vital role in negatively regulating the development and the progression of NAFLD by acting on multiple cellular pathways.

\section{SIRT3 and NAFLD}

SIRT3 is a NAD-dependent deacetylase localized in the mitochondrial matrix [44, 45, 69-71]. SIRT3 is a global regulator of mitochondrial protein acetylation with the capability to coordinate cellular responses to nutrient status and energy homeostasis [72-77]. SIRT3 is expressed in the liver, adipose tissue, heart, brain, and kidney $[71,73]$ and regulates $\beta$-oxidation, ketogenesis, mitophagy, and stress-related pathways (Figure 2) [74, 78-83]. The expression of SIRT3 is activated during fasting and calorie restriction [82, 84, 85], while chronic HFD and obesity reduce SIRT3 activity [86] (Figure 2). In the absence of SIRT3, mitochondrial proteins become hyperacetylated, mitochondrial function impaired, leading to NAFLD [76, 82, 87] (Figure 2). At least $65 \%$ of all mitochondrial proteins from the liver tissue of SIRT3 knockout (KO) mice have at least one lysine-acetylated [85]. SIRT3 regulates proteins of the mitochondrial electron transport chain such as complex I [87], succinate dehydrogenase A of complex II [88, 89], and ATP synthase (complex V) [90] and increase ATP production (Figure 2) [87]. Basal levels of ATP in the liver is reduced by $50 \%$ in mice lacking SIRT3 [87]. SIRT3 promotes $\beta$-oxidation by activating long-chain acyl CoA dehydrogenase (LCAD) activity and ketone body generation by promoting the deacetylation of 3-hydroxy-3-methylglutaryl CoA synthase 2 (AceCS2) [79, 82, 84, 85] (Figure 2). Fasting upregulates SIRT3, induces LCAD and increases its activity [82]. LCAD deficiency is also associated with reduced $\beta$-oxidation, increased lipid accumulation, and the development of insulin resistance and steatohepatitis in mice $[91,92]$. Mitochondrial trifunctional protein (MTP) catalyzes the last three steps in $\beta$-oxidation. Heterozygous MTP KO $\left(\mathrm{MTP}^{+-}\right)$mice have reduced SIRT3 levels, reduced $\beta$-oxidation, and develop fatty liver [74, 93] (Figure 2). Overexpression of SIRT3 in $\mathrm{MTP}^{+/-}$ mice deacetylates MTP increases its hepatic levels and increased mitochondrial function [74] (Figure 2). Interestingly, the hydroxy acyl-CoA dehydrogenase (HADHA), the $\alpha$-subunit of the MTP complex, was found to be highly regulated by SIRT3 [73].

SIRT3 also modulates oxygen consumption and reactive oxygen species (ROS) levels in hepatocytes $[86,94]$. SIRT3 deacetylates superoxide dismutase (SOD2), which converts $\mathrm{O}^{-2}$ to $\mathrm{H}_{2} \mathrm{O}_{2}$ and enhances its ability to scavenge ROS [77, 95] (Figure 2). Consistently, SIRT3 KO mice exhibit decreased SOD2 activity and increased oxidative stress, suggesting a role of SIRT3 in NASH [95]. Moreover, SIRT3 activates isocitrate dehydrogenase 2 (IDH2), a crucial enzyme that promotes the restoration of antioxidant capability [96, 97] (Figure 2). SIRT3 KO mice subjected to a methionine and choline-deficient diet, a classical dietary model of NASH, exhibit increased hepatic lipid content associated with increased serum ALT levels, reduced SOD2 activity, and increased 
expression of inflammatory [TNF $\alpha$, interleukin $\beta 1$, inducible nitric oxide synthase (iNOS)] and fibrogenic [collagen 1 and alpha-smooth muscle actin ( $\alpha$ SMA)] genes [98]. However, overexpression of SIRT3 results in opposite effects supporting an essential role of SIRT3 in NAFLD and NASH [99]. In addition, chronic HFD is associated with hepatocellular damage, and this is associated with reduced hepatic SIRT3 [94]. Interestingly, SIRT3 overexpression in mice restored hepatic function and reversed liver fibrosis, inflammation, and hepatocyte apoptosis [83].

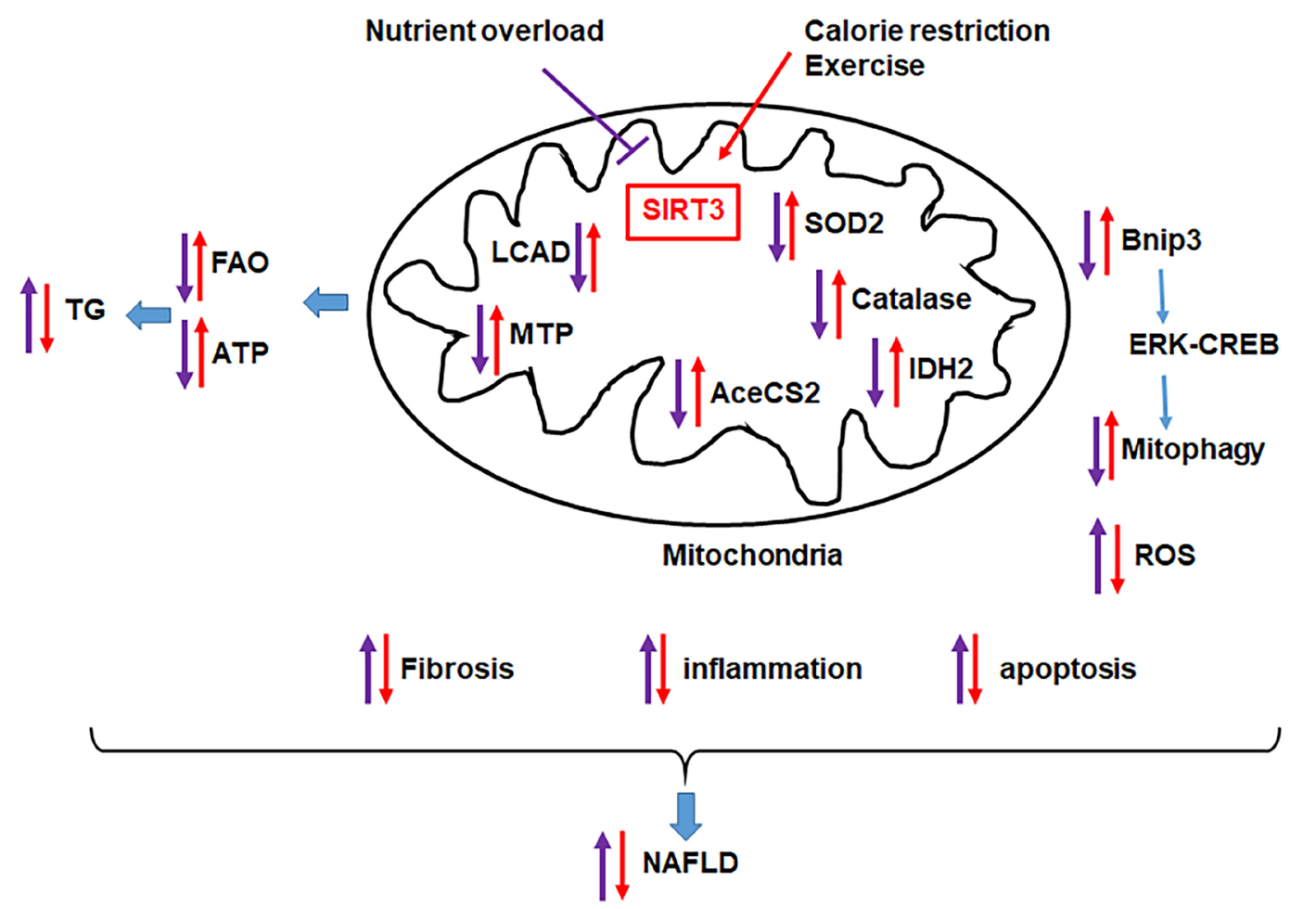

Figure 2. SIRT3 protects the liver from nutrient overload-induced NAFLD. Nutrient overload triggers metabolic reprogramming that leads to hepatic lipid accumulation and liver injury due to reduced mitochondrial function (FAO, ATP production), increased inflammation, reduced mitophagy. Factors that increase hepatic SIRT3, such as dietary restriction and exercise, counteract the effect of nutrient overload and improve NAFLD

Recently Cheng et al. [100] identified SIRT3 as a target for the differentially expressed microRNA-421 (miRNA-421) in HFD-fed mice compared with controls. miRNA-421 decreases SIRT3 and FOXO3 protein levels, as well as the downstream antioxidant targets SOD2 and catalase [100]. The progression of NAFLD in SIRT3 KO mice is associated with diet-induced mitochondrial damage [101]. SIRT3 overexpression protected hepatocytes against mitochondrial apoptosis via promoting Bnip3-required mitophagy [83] (Figure 2). Gut microbiota imbalance also contributes to the pathogenesis of NAFLD $[8,65]$. Lack of SIRT3 results in an impaired intestinal permeability in HFD-fed mice through gut microbiota dysbiosis and inflammation [102]. Together the available finding indicates a protective role of SIRT3 in NAFLD and NASH.

\section{Conclusion and future directions}

NAFLD is a silent epidemic increasing with the increase in obesity. Apart from lifestyle modifications such as diet and physical activity, no approved pharmacological options currently exist to treat NAFLD. Regulation of proteins by acetylation mimics the effect of exercise and caloric restriction, the current recommended method for the management of NAFLD and NASH, with SIRT1 and SIRT3 having a protective role against the development and the progression of the disease. Proteins with differential acetylation levels could be a potential diagnostic marker and target for the treatment of NAFLD. Further studies are needed to determine the interaction between the different sirtuins and how this affects the metabolic pathways in the liver. The nature of the crosstalk between the different PMPs and their role in the modulation NAFLD is an area that needs more investigation. The discovery of selective and potent SIRTs activators and inhibitors is still in its early stages. More studies are needed to develop specific activators and inhibitors of SIRTs activity as well as agonists that target a particular cellular compartment. 


\section{Abbreviations}

acetyl-CoA: acetyl-coenzyme A

ChREBP: carbohydrate-responsive element-binding protein

CREBH: cyclic AMP-responsive element-binding protein 3-like 3-hepatocyte-specific

DNL: de novo lipogenesis

FA: fatty acid

FAO: fatty acid oxidation

HFD: high-fat diet

KO: knockout

LCAD: long-chain acyl CoA dehydrogenase

MTP: mitochondrial trifunctional protein

NAD: nicotinamide adenine dinucleotide

NAFLD: nonalcoholic fatty liver disease

NASH: nonalcoholic steatohepatitis

PMPs: posttranslational modifications of proteins

PPAR $\alpha$ : peroxisome proliferator-activated receptors

PTM: posttranslational modification

ROS: reactive oxygen species

SIRT: sirtuin

SOD2: superoxide dismutase 2

SREBP-1c: sterol regulatory element-binding transcription factor $1 \mathrm{c}$

TG: triglyceride

\section{Declarations}

\section{Author contributions}

The author contributed solely to the work.

\section{Conflicts of interest}

The author declares that there are no conflicts of interest.

\section{Ethical approval}

Not applicable.

\section{Consent to participate}

Not applicable.

\section{Consent to publication}

Not applicable.

\section{Availability of data and materials}

Not applicable.

\section{Funding}

The University of Missouri Research Board grant to Fatiha Nassir; the funder had no role in the design and preparation of the manuscript, or decision to publish the manuscript. 


\section{Copyright}

(C) The Author(s) 2020.

\section{References}

1. Younossi Z, Anstee QM, Marietti M, Hardy T, Henry L, Eslam M, et al. Global burden of NAFLD and NASH: trends, predictions, risk factors and prevention. Nat Rev Gastroenterol Hepatol. 2018;15:11-20.

2. Williams CD, Stengel J, Asike MI, Torres DM, Shaw J, Contreras M, et al. Prevalence of nonalcoholic fatty liver disease and nonalcoholic steatohepatitis among a largely middle-aged population utilizing ultrasound and liver biopsy: a prospective study. Gastroenterology. 2011;140:124-31.

3. Sayiner M, Koenig A, Henry L, Younossi ZM. Epidemiology of nonalcoholic fatty liver disease and nonalcoholic steatohepatitis in the United States and the rest of the world. Clin Liver Dis. 2016;20:205-14.

4. Rinella ME. Nonalcoholic fatty liver disease: a systematic review. JAMA. 2015;313:2263-73.

5. Chalasani N, Younossi Z, Lavine JE, Charlton M, Cusi K, Rinella M, et al. The diagnosis and management of nonalcoholic fatty liver disease: practice guidance from the American Association for the Study of Liver Diseases. Hepatology. 2018;67:328-57.

6. Buzzetti E, Pinzani M, Tsochatzis EA. The multiple-hit pathogenesis of non-alcoholic fatty liver disease (NAFLD). Metabolism. 2016;65:1038-48.

7. Tilg H, Hotamisligil GS. Nonalcoholic fatty liver disease: cytokine-adipokine interplay and regulation of insulin resistance. Gastroenterology. 2006;131:934-45.

8. Kolodziejczyk AA, Zheng D, Shibolet O, Elinav E. The role of the microbiome in NAFLD and NASH. EMBO Mol Med. 2019;11:e9302.

9. Nassir F, Ibdah JA. Role of mitochondria in nonalcoholic fatty liver disease. Int J Mol Sci. 2014;15:8713-42.

10. Ipsen DH, Lykkesfeldt J, Tveden-Nyborg P. Molecular mechanisms of hepatic lipid accumulation in nonalcoholic fatty liver disease. Cell Mol Life Sci. 2018;75:3313-27.

11. Walsh CT, Garneau-Tsodikova S, Gatto GJ Jr. Protein posttranslational modifications: the chemistry of proteome diversifications. Angew Chem Int Ed Engl. 2005;44:7342-72.

12. SpoelSH. Orchestrating the proteome with post-translational modifications.J Exp Bot. 2018;69:4499-503.

13. Yang XJ, Seto E. Lysine acetylation: codified crosstalk with other posttranslational modifications. Mol cell. 2008;31:449-61.

14. Nguyen P, Leray V, Diez M, Serisier S, Le Bloc'h J, Siliart B, et al. Liver lipid metabolism. J Anim Physiol Anim Nutr (Berl). 2008;92:272-83.

15. Smith GI, Shankaran M, Yoshino M, Schweitzer GG, Chondronikola M, Beals JW, et al. Insulin resistance drives hepatic de novo lipogenesis in nonalcoholic fatty liver disease. J Clin Invest. 2020;130:1453-60.

16. Hodson L, McQuaid SE, Humphreys SM, Milne R, Fielding BA, Frayn KN, et al. Greater dietary fat oxidation in obese compared with lean men: an adaptive mechanism to prevent liver fat accumulation? Am J Physiol Endocrinol Metab. 2010;299:E584-92.

17. Lazarin MDO, Ishii-Iwamoto EL, Yamamoto NS, Constantin RP, Garcia RF, da Costa CE, et al. Liver mitochondrial function and redox status in an experimental model of non-alcoholic fatty liver disease induced by monosodium L-glutamate in rats. Exp Mol Pathol. 2011;91:687-94.

18. Zhang Y, Marcillat O, Giulivi C, Ernster L, Davies KJ. The oxidative inactivation of mitochondrial electron transport chain components and ATPase. J Biol Chem. 1990;265:16330-6.

19. Sadek HA, Szweda PA, Szweda LI. Modulation of mitochondrial complex I activity by reversible $\mathrm{Ca}^{2+}$ and NADH mediated superoxide anion dependent inhibition. Biochemistry. 2004;43:8494-502.

20. Verdin E, Ott M. 50 years of protein acetylation: from gene regulation to epigenetics, metabolism and beyond. Nat Rev Mol Cell Biol. 2015;16:258-64.

21. Phillips DM. The presence of acetyl groups of histones. Biochem J. 1963;87:258-63. 
22. Choudhary C, Weinert BT, Nishida Y, Verdin E, Mann M. The growing landscape of lysine acetylation links metabolism and cell signalling. Nat Rev Mol Cell Biol. 2014;15:536-50.

23. Glozak MA, Sengupta N, Zhang X, Seto E. Acetylation and deacetylation of non-histone proteins. Gene. 2005;363:15-23.

24. Zhao S, Xu W, Jiang W, Yu W, Lin Y, Zhang T, et al. Regulation of cellular metabolism by protein lysine acetylation. Science. 2010;327:1000-4.

25. Choudhary C, Kumar C, Gnad F, Nielsen ML, Rehman M, Walther TC, et al. Lysine acetylation targets protein complexes and co-regulates major cellular functions. Science. 2009;325:834-40.

26. Kim SC, Sprung R, Chen Y, Xu Y, Ball H, Pei J, et al. Substrate and functional diversity of lysine acetylation revealed by a proteomics survey. Mol Cell. 2006;23:607-18.

27. Mertins P, Qiao JW, Patel J, Udeshi ND, Clauser KR, Mani DR, et al. Integrated proteomic analysis of posttranslational modifications by serial enrichment. Nat Methods. 2013;10:634-7.

28. Kim GW, Gocevski G, Wu CJ, Yang XJ. Dietary, metabolic, and potentially environmental modulation of the lysine acetylation machinery. Int J Cell Biol. 2010;2010:632739.

29. Aksnes H, Drazic A, Marie M, Arnesen T. First things first: vital protein marks by N-terminal acetyltransferases. Trends Biochem Sci. 2016;41:746-60.

30. Ande SR, Padilla-Meier GP, Mishra S. Mutually exclusive acetylation and ubiquitylation among enzymes involved in glucose metabolism. Adipocyte. 2013;2:256-61.

31. Wu Z, Huang R, Yuan L. Crosstalk of intracellular post-translational modifications in cancer. Arch Biochem Biophys. 2019;676:108138.

32. Le-Tian Z, Cheng-Zhang H, Xuan Z, Zhang Q, Zhen-Gui Y, Qing-Qing W, et al. Protein acetylation in mitochondria plays critical functions in the pathogenesis of fatty liver disease. BMC Genomics. 2020;21:435.

33. Kim H, Mendez R, Chen X, Fang D, Zhang K. Lysine acetylation of CREBH regulates fasting-induced hepatic lipid metabolism. Mol Cell Biol. 2015;35:4121-34.

34. Zhang C, Wang G, Zheng Z, Maddipati KR, Zhang X, Dyson G, et al. Endoplasmic reticulum-tethered transcription factor cAMP responsive element-binding protein, hepatocyte specific, regulates hepatic lipogenesis, fatty acid oxidation, and lipolysis upon metabolic stress in mice. Hepatology. 2012;55:1070-82.

35. Nakagawa Y, Shimano H. CREBH regulates systemic glucose and lipid metabolism. Int J Mol Sci. 2018;19:1396.

36. Bricambert J, Miranda J, Benhamed F, Girard J, Postic C, Dentin R. Salt-inducible kinase 2 links transcriptional coactivator p300 phosphorylation to the prevention of ChREBP-dependent hepatic steatosis in mice. J Clin Invest. 2010;120:4316-31.

37. Chen S, Feng B, George B, Chakrabarti R, Chen M, Chakrabarti S. Transcriptional coactivator p300 regulates glucose-induced gene expression in endothelial cells. Am J Physiol Endocrinol Metab. 2010;298:E127-37.

38. Silva JP, Wahlestedt C. Role of Sirtuin 1 in metabolic regulation. Drug Discov Today. 2010;15:781-91.

39. Gomes AR, Yong JS, Kiew KC, Aydin E, Khongkow M, Laohasinnarong S, et al. Sirtuin1 (SIRT1) in the acetylation of downstream target proteins. Methods Mol Biol. 2016;1436:169-88.

40. Cheng J, Liu C, Hu K, Greenberg A, Wu D, Ausman LM, et al. Ablation of systemic SIRT1 activity promotes nonalcoholic fatty liver disease by affecting liver-mesenteric adipose tissue fatty acid mobilization. Biochim Biophys Acta Mol Basis Dis. 2017;1863:2783-90.

41. Li M, Hong W, Hao C, Li L, Wu D, Shen A, et al. SIRT1 antagonizes liver fibrosis by blocking hepatic stellate cell activation in mice. FASEB J. 2018;32:500-11. 
42. Haigis MC, Guarente LP. Mammalian sirtuins--emerging roles in physiology, aging, and calorie restriction. Genes Dev. 2006;20:2913-21.

43. Colak Y, Ozturk O, Senates E, Tuncer I, Yorulmaz E, Adali G, et al. SIRT1 as a potential therapeutic target for treatment of nonalcoholic fatty liver disease. Med Sci Monit. 2011;17:HY5-9.

44. Nogueiras R, Habegger KM, Chaudhary N, Finan B, Banks AS, Dietrich MO, et al. Sirtuin 1 and sirtuin 3: physiological modulators of metabolism. Physiol Rev. 2012;92:1479-514.

45. Michishita E, Park JY, Burneskis JM, Barrett JC, Horikawa I. Evolutionarily conserved and nonconserved cellular localizations and functions of human SIRT proteins. Mol Biol Cell. 2005;16:4623-35.

46. Lam YY, Peterson CM, Ravussin E. Resveratrol vs. calorie restriction: data from rodents to humans. Exp Gerontol. 2013;48:1018-24.

47. Colak Y, Yesil A, Mutlu HH, Caklili OT, Ulasoglu C, Senates E, et al. A potential treatment of non-alcoholic fatty liver disease with SIRT1 activators. J Gastrointestin Liver Dis. 2014;23:311-9.

48. Pfluger PT, Herranz D, Velasco-Miguel S, Serrano M, Tschöp MH. Sirt1 protects against high-fat dietinduced metabolic damage. Proc Natl Acad Sci U S A. 2008;105:9793-8.

49. Tang BL. Sirt1 and the mitochondria. Mol Cells. 2016;39:87-95.

50. Wu T, Liu YH, Fu YC, Liu XM, Zhou XH. Direct evidence of sirtuin downregulation in the liver of nonalcoholic fatty liver disease patients. Ann Clin Lab Sci. 2014;44:410-8.

51. Ding RB, Bao J, Deng CX. Emerging roles of SIRT1 in fatty liver diseases. Int J Biol Sci. 2017;13:852-67.

52. Deng XQ Chen LL, Li NX. The expression of SIRT1 in nonalcoholic fatty liver disease induced by high-fat diet in rats. Liver Int. 2007;27:708-15.

53. Wang Y. Molecular links between caloric restriction and Sir2/SIRT1 activation. Diabetes Metab J. 2014;38:321-9.

54. Chen D, Bruno J, Easlon E, Lin SJ, Cheng HL, Alt FW, et al. Tissue-specific regulation of SIRT1 by calorie restriction. Genes Dev. 2008;22:1753-7.

55. Suter MA, Chen A, Burdine MS, Choudhury M, Harris RA, Lane RH, et al. A maternal high-fat diet modulates fetal SIRT1 histone and protein deacetylase activity in nonhuman primates. FASEB J. 2012;26:5106-14.

56. Bruce KD, Cagampang FR, Argenton M, Zhang J, Ethirajan PL, Burdge GC, et al. Maternal high-fat feeding primes steatohepatitis in adult mice offspring, involving mitochondrial dysfunction and altered lipogenesis gene expression. Hepatology. 2009;50:1796-808.

57. Bruce KD, Szczepankiewicz D, Sihota KK, Ravindraanandan M, Thomas H, Lillycrop KA, et al. Altered cellular redox status, sirtuin abundance and clock gene expression in a mouse model of developmentally primed NASH. Biochim Biophys Acta. 2016;1861:584-93.

58. Tian Y, Ma J, Wang W, Zhang L, Xu J, Wang K, et al. Resveratrol supplement inhibited the NF-кB inflammation pathway through activating AMPK $\alpha$-SIRT1 pathway in mice with fatty liver. Mol Cell Biochem. 2016;422:75-84.

59. Denechaud PD, Bossard P, Lobaccaro JMA, Millatt L, Staels B, Girard J, et al. ChREBP, but not LXRs, is required for the induction of glucose-regulated genes in mouse liver. J Clin Invest. 2008;118:956-64.

60. Strable MS, Ntambi JM. Genetic control of de novo lipogenesis: role in diet-induced obesity. Crit Rev Biochem Mol Biol. 2010;45:199-214.

61. Ponugoti B, Kim DH, Xiao Z, Smith Z, Miao J, Zang M, et al. SIRT1 deacetylates and inhibits SREBP-1C activity in regulation of hepatic lipid metabolism. J Biol Chem. 2010;285:33959-70.

62. Cheng CF, Ku HC, Lin H. PGC- $1 \alpha$ as a pivotal factor in lipid and metabolic regulation. Int J Mol Sci. 2018;19:3447.

63. Rodgers JT, Lerin C, Gerhart-Hines Z, Puigserver P. Metabolic adaptations through the PGC-1 $\alpha$ and SIRT1 pathways. FEBS Lett. 2008;582:46-53. 
64. Purushotham A, Schug TT, Xu Q, Surapureddi S, Guo X, Li X. Hepatocyte-specific deletion of SIRT1 alters fatty acid metabolism and results in hepatic steatosis and inflammation. Cell Metab. 2009;9:327-38.

65. Pushpanathan P, Mathew GS, Selvarajan S, Seshadri KG, Srikanth P. Gut microbiota and its mysteries. Indian J Med Microbiol. 2019;37:268-77.

66. Yoshii SR, Mizushima N. Autophagy machinery in the context of mammalian mitophagy. Biochim Biophys Acta. 2015;1853:2797-801.

67. Andrade JMO, Paraíso AF, de Oliveira MV, Martins AME, Neto JF, Guimarães ALS, et al. Resveratrol attenuates hepatic steatosis in high-fat fed mice by decreasing lipogenesis and inflammation. Nutrition. 2014;30:915-9.

68. Niu B, He K, Li P, Gong J, Zhu X, Ye S, et al. SIRT1 upregulation protects against liver injury induced by a HFD through inhibiting CD36 and the NF-кB pathway in mouse kupffer cells. Mol Med Rep. 2018;18:1609-15.

69. Onyango P, Celic I, McCaffery JM, Boeke JD, Feinberg AP. SIRT3, a human SIR2 homologue, is an NADdependent deacetylase localized to mitochondria. Proc Natl Acad Sci U S A. 2002;99:13653-8.

70. Kim HS, Patel K, Muldoon-Jacobs K, Bisht KS, Aykin-Burns N, Pennington JD, et al. SIRT3 is a mitochondrialocalized tumor suppressor required for maintenance of mitochondrial integrity and metabolism during stress. Cancer Cell. 2010;17:41-52.

71. Schwer B, North BJ, Frye RA, Ott M, Verdin E. The human silent information regulator (Sir)2 homologue hSIRT3 is a mitochondrial nicotinamide adenine dinucleotide-dependent deacetylase. J Cell Biol. 2002;158:647-57.

72. Shi T, Wang F, Stieren E, Tong Q. SIRT3, a mitochondrial sirtuin deacetylase, regulates mitochondrial function and thermogenesis in brown adipocytes. J Biol Chem. 2005;280:13560-7.

73. Rardin MJ, Newman JC, Held JM, Cusack MP, Sorensen DJ, Li B, et al. Label-free quantitative proteomics of the lysine acetylome in mitochondria identifies substrates of SIRT3 in metabolic pathways. Proc Natl Acad Sci U S A. 2013;110:6601-6.

74. Nassir F, Arndt JJ, Johnson SA, Ibdah JA. Regulation of mitochondrial trifunctional protein modulates nonalcoholic fatty liver disease in mice. J Lipid Res. 2018;59:967-73.

75. Nassir F, Ibdah JA. Sirtuins and nonalcoholic fatty liver disease. World J Gastroenterol. 2016;22:10084-92.

76. Lombard DB, Alt FW, Cheng HL, Bunkenborg J, Streeper RS, Mostoslavsky R, et al. Mammalian Sir2 homolog SIRT3 regulates global mitochondrial lysine acetylation. Mol Cell Biol. 2007;27:8807-14.

77. Qiu X, Brown K, Hirschey MD, Verdin E, Chen D. Calorie restriction reduces oxidative stress by SIRT3mediated SOD2 activation. Cell Metab. 2010;12:662-7.

78. Hallows WC, Yu W, Smith BC, Devries MK, Ellinger JJ, Someya S, et al. Sirt3 promotes the urea cycle and fatty acid oxidation during dietary restriction. Mol Cell. 2011;41:139-49.

79. Schwer B, Bunkenborg J, Verdin RO, Andersen JS, Verdin E. Reversible lysine acetylation controls the activity of the mitochondrial enzyme acetyl-CoA synthetase 2. Proc Natl Acad Sci U S A. 2006;103:10224-9.

80. Anderson KA, Hirschey MD. Mitochondrial protein acetylation regulates metabolism. Essays Biochem. 2012;52:23-35.

81. Hirschey MD, Shimazu T, Huang JY, Schwer B, Verdin E. SIRT3 regulates mitochondrial protein acetylation and intermediary metabolism. Cold Spring Harb Symp Quant Biol. 2011;76:267-77.

82. Hirschey MD, Shimazu T, Goetzman E, Jing E, Schwer B, Lombard DB, et al. SIRT3 regulates mitochondrial fatty-acid oxidation by reversible enzyme deacetylation. Nature. 2010;464:121-5.

83. Li R, Xin T, Li D, Wang C, Zhu H, Zhou H. Therapeutic effect of Sirtuin 3 on ameliorating nonalcoholic fatty liver disease: the role of the ERK-CREB pathway and Bnip3-mediated mitophagy. Redox Biol. 2018;18:229-43.

84. Hirschey MD, Shimazu T, Capra JA, Pollard KS, Verdin E. SIRT1 and SIRT3 deacetylate homologous substrates: AceCS1,2 and HMGCS1,2. Aging (Albany NY). 2011;3:635-42. 
85. Hebert AS, Dittenhafer-Reed KE, Yu W, Bailey DJ, Selen ES, Boersma MD, et al. Calorie restriction and SIRT3 trigger global reprogramming of the mitochondrial protein acetylome. Mol Cell. 2013;49:186-99.

86. Bao J, Scott I, Lu Z, Pang L, Dimond CC, Gius D, et al. SIRT3 is regulated by nutrient excess and modulates hepatic susceptibility to lipotoxicity. Free Radic Biol Med. 2010;49:1230-7.

87. Ahn BH, Kim HS, Song S, Lee IH, Liu J, Vassilopoulos A, et al. A role for the mitochondrial deacetylase Sirt3 in regulating energy homeostasis. Proc Natl Acad Sci U S A. 2008;105:14447-52.

88. Cimen H, Han MJ, Yang Y, Tong Q, Koc H, Koc EC. Regulation of succinate dehydrogenase activity by SIRT3 in mammalian mitochondria. Biochemistry. 2010;49:304-11.

89. Finley LWS, Haas W, Desquiret-Dumas V, Wallace DC, Procaccio V, Gygi SP, et al. Succinate dehydrogenase is a direct target of sirtuin 3 deacetylase activity. PLoS One. 2011;6:e23295.

90. Vassilopoulos A, Pennington JD, Andresson T, Rees DM, Bosley AD, Fearnley IM, et al. SIRT3 deacetylates ATP synthase F1 complex proteins in response to nutrient- and exercise-induced stress. Antioxid Redox signal. 2014;21:551-64.

91. Zhang D, Liu ZX, Choi CS, Tian L, Kibbey R, Dong J, et al. Mitochondrial dysfunction due to long-chain acyl-CoA dehydrogenase deficiency causes hepatic steatosis and hepatic insulin resistance. Proc Natl Acad Sci U S A. 2007;104:17075-80.

92. Kurtz DM, Rinaldo P, Rhead WJ, Tian L, Millington DS, Vockley J, et al. Targeted disruption of mouse longchain acyl-CoA dehydrogenase gene reveals crucial roles for fatty acid oxidation. Proc Natl Acad Sci U S A. 1998;95:15592-7.

93. Ibdah JA, Perlegas P, Zhao Y, Angdisen J, Borgerink H, Shadoan MK, et al. Mice heterozygous for a defect in mitochondrial trifunctional protein develop hepatic steatosis and insulin resistance. Gastroenterology. 2005;128:1381-90.

94. Liu J, Li D, Zhang T, Tong Q, Ye RD, Lin L. SIRT3 protects hepatocytes from oxidative injury by enhancing ROS scavenging and mitochondrial integrity. Cell Death Dis. 2017;8:e3158.

95. Tao R, Coleman MC, Pennington JD, Ozden O, Park SH, Jiang H, et al. Sirt3-mediated deacetylation of evolutionarily conserved lysine 122 regulates MnSOD activity in response to stress. Mol Cell. 2010;40:893-904.

96. Yu W, Dittenhafer-Reed KE, Denu JM. SIRT3 protein deacetylates isocitrate dehydrogenase 2 (IDH2) and regulates mitochondrial redox status. J Biol Chem. 2012;287:14078-86.

97. Someya S, Yu W, Hallows WC, Xu J, Vann JM, Leeuwenburgh C, et al. Sirt3 mediates reduction of oxidative damage and prevention of age-related hearing loss under caloric restriction. Cell. 2010;143:802-12.

98. He J, Hu B, Shi X, Weidert ER, Lu P, Xu M, et al. Activation of the aryl hydrocarbon receptor sensitizes mice to nonalcoholic steatohepatitis by deactivating mitochondrial sirtuin deacetylase Sirt3. Mol Cell Biol. 2013;33:2047-55.

99. Alberdi G, Rodríguez VM, Macarulla MT, Miranda J, Churruca I, Portillo MP. Hepatic lipid metabolic pathways modified by resveratrol in rats fed an obesogenic diet. Nutrition. 2013;29:562-7.

100. Cheng Y, Mai J, Hou T, Ping J. MicroRNA-421 induces hepatic mitochondrial dysfunction in non-alcoholic fatty liver disease mice by inhibiting sirtuin 3. Biochem Biophys Res Commun. 2016;474:57-63.

101. Fromenty B, Robin MA, Igoudjil A, Mansouri A, Pessayre D. The ins and outs of mitochondrial dysfunction in NASH. Diabetes Metab. 2004;30:121-38.

102. Chen M, Hui S, Lang H, Zhou M, Zhang Y, Kang C, et al. SIRT3 deficiency promotes high-fat diet-induced nonalcoholic fatty liver disease in correlation with impaired intestinal permeability through gut microbial dysbiosis. Mol Nutr Food Res. 2019;63:e1800612. 